small one, will consist of representatives of the Colonial Office, and members of the Trades Union Congress and of employers' organizations interested in Colonial affairs. The Colonial Office already has a labour adviser, and the new Committee will serve to strengthen this side of its work. It may be anticipated that as the various provisions of the Welfare and Development Act come more extensively in force, this Committee will grow in importance and its activities play a prominent part in the future of the British Colonial Empire.

A brief survey of Colonial Office activities during the past year was also given by Mr. Hall. Even under war-time conditions it has been possible to send officials of the Colonial Office overseas to examine problems on the spot. Lord Hailey is presiding over a committee examining post-war problems which are likely to arise. Many schemes, amounting to hundreds of thousands of pounds, submitted under the Welfare and Development Act, have been approved. The appointment of an economic and financial adviser to work with Sir Frank Stockdale is being considered. The needs of Colonial peoples in Great Britain have also been examined; a welfare officer and an assistant welfare officer, the latter an African, have been appointed, and an adviser to Colonial students, who is a West Indian, is being appointed. Mr. Hall concluded by emphasizing that our duty is now to improve the lot of the Colonial peoples, to develop their resources so as to raise their standard of living, and to enable them to take an ever-increasing responsibility in their own government.

\section{Federation of American Societies for Experimental Biology}

Is March 1942 the Federation of American Societies for Experimental Biology will issue the first number of a quarterly publication to be named the Federation Proceedings. This will be published by an editorial board representing the five constituent societies of the Federation : the American Physiological Society, the American Society of Biological Chemists, the American Society for Pharmacology and Experimental Therapeutics, the American Society for Experimental Pathology, and the American Institute of Nutrition. Four numbers will be published each year. The March issue will appear just previous to the annual meeting of the Federation, and will be composed of two parts. Part 1 will include the abstracts of all the papers to be presented at the annual meeting, about a thousand in all. Part 2 will comprise the programme of the scientific sessions of all the constituent societies of the Federation. The June and September issues will include the full text of perhaps twenty of the papers presented at the annual meeting as selected by the editorial board, including probably the papers on the joint programme of the Federation as a whole as well as the papers of one symposium of each of the five societies. The December issue will include material pertinent to the Federation membership formerly published in the Federation Yearbook, which will hereafter be discontinued. The Federation Proceedings will be distributed without further charge to all members of the Federation. The subscription price to non-members will be four dollars (4.50 dollars foreign) payable in advance. Further information can be obtained from Dr. D. R. Hooker, Managing Editor, 19 West Chase Street, Baltimore, Maryland.

\section{Therapeutic Research Corporation}

A NEW step in the rationalization of the British fine chemical industry has been taken by the formation of the Therapeutic Research Corporation of Great Britain, Ltd., the directors of which are Lord Trent, of Boots Pure Drug Company, Ltd., Mr. C. A. Hill, of the British Drug Houses, Ltd., Mr. H. Jephcott, of Glaxo Laboratories, Ltd., Mr. T. B. Maxwell, of May and Baker, Ltd., and Mr. T. R. G. Bennett, of the Wellcome Foundation, Ltd. Although each of the directors of the new Corporation is managing director of his own concern, the Corporation is not an amalgamation of these five firms. Each will retain its freedom of action in its special field, but will contribute to the common research pool ; in effect, a much extended research team now becomes available for work on new drugs, and overlapping effort should be eliminated. It is also hoped to secure the interest and co-operation of research workers in academic institutions. The Corporation will have in the various chemical, physiological and bacteriological laboratories at its command the choice of many differęnt lines of approach to its problems and the call on the extensive scientific personnel and equip. ment of the five companies which are collaborating. This should make for a hopeful start and lay the foundation of a promising superstructure.

\section{Norway: Present and Future}

Mr. GATHORNE-HARDY's pamphlet. "Norway and the War" (Oxford Pamphlets on World Affairs, No. 51. 4d. net) gives an account of the physical characteristics and resources of Norway, its people and their democracy, and relations with their Scandinavian neighbours and other powers, which could scarcely be bettered as a contribution to the understanding of the Norwegian resistance to Nazism and of Norway's future. Although little more than a third of the pamphlet deals with Norway and the War proper, the pamphlet contains nothing irrelevant, and it emphasizes the close ties between Norway and Great Britain through the marked similarity of outlook, the ties of the sea, and the long association of various kinds.

Despite the appeal of Germany in scientific and technical circles, Norwegian thought, with its passionate insistence on individual liberty, free speech and parliamentary democracy, is diametrically opposed to the totalitarian ideology, and her neutrality had no spiritual basis. Mr. GathorneHardy emphasizes the important part which confusion, rather than deliberate treachery, played in the situation when Norway was invaded, and also the credit due to the Norwegians for the toughness of their resistance in a singularly desperate situation. After a brief account of the German occupation, he 
indicates the re-orientation which is taking place in Norwegian foreign policy, now that isolated neutrality and Scandinavian collaboration have proved insufficient security. As an Atlantic and seafaring nation, Norway seems likely to look for help and collaboration mainly to the free nations overseasthe British Empire and the United States.

\section{Recent Earthquakes}

According to a message in The Times, a violent earthquake was experienced about noon (local time) on November 12 at Erzinjan in Anatolia. A number of buildings were damaged in the town but only a few persons were injured. It is feared that the damage and casualties will be greater in the villages near Erzinjan, and further information is awaited. It will be recalled that a very great earthquake struck the same region on December 27, 1939 (NATURE, January 6, 1940, p. 13).

An earthquake of considerable severity (probably the most severe for eight years) shook Los Angeles on November 14. The electric power station in the Beverly Hills district was temporarily stopped and about a hundred small buildings together with some oil storage tanks were wrecked. Gas and water mains were broken, and some suburban homes in the Torrance Gardena district were damaged. Several parked motor-cars were damaged when the front of a store fell into the street. Damage in one district is estimated at a million dollars. No deaths or serious injuries are reported and further information is awaited. Los Angeles and Hollywood were affected by strong earthquakes on October 11, 1940 (NATURE, November 30, 1940, p. 720), and January 28, 1931, besides numerous other occasions.

\section{Dr. George Birkbeck and Technical Education}

ON December 1, a century ago, Dr. George Birkbeck died in London and was buried in Kensal Green Cemetery. His name to-day is recalled by Birkbeck College, London, which began its career as the London Mechanies' Institution with Birkbeck as its president. There were at one time hundreds of such institutions, and no doubt many of them exist to-day, but they may all be said to have sprung from the classes for mechanics started by Birkbeck in 1800 at the Anderson College of Glasgow, in which as a young man of twenty-four he held the chair of natural philosophy. Born in Settle, Yorkshire, on January 10, 1776, Birkbeck studied medicine at Leeds, London and Edinburgh, but he began his active career as a lecturer. In $\mathbf{1 8 0 4}$ he set up in practice in the City of London and there became known to Hume, Grote, Brougham, and many other men of liberal ideas. In 1809 he assisted in founding the London Institution, in 1824 became president of the Mechanics' Institution, and was a projector of University College, and a supporter of the Society for the Diffusion of Useful Knowledge. He was, as his biographer J. G. Godard says, a "National Reformer". In the prospectus of his class of 1800 , he stated that it was "for persons engaged in the exercise of the mechanical arts, whose education in early life has precluded even the possi- bility of acquiring the smallest portion of scientific knowledge". He lived to see knowledge brought within the reach of all.

\section{Recent Investigation of New Plant Fibres}

AN investigation has been carried out by the Royal Botanic Gardens, Kew, in collaboration with the National Physical and Chemical Laboratories and the Imperial Institute, of the mechanical properties of the fibre from nettle stems (Urtica dioica) and other plants native to Great Britain, and of methods of extraction. The nettle fibre has been found to be suitable for the manufacture of high-grade paper, and possibly of textiles, while the leaves are commercially valuable for the extraction of chlorophyll. Arrangements were made for the extensive collection of this abundant raw material during 1941 .

\section{The Night Sky in December}

THE moon is full on Dec. 3d. 20h. 5Im. U.T. and new on Dec. 18d. 10h. $20 \mathrm{~m}$. Lunar conjunctions with the planets occur on the following dates: Saturn on Dec. 2d. 9h., Saturn $2^{\circ}$ N. ; Jupiter on Dec. 4 d. 7h., Jupiter $4^{\circ}$ N. ; Venus on Dec. 21 d. 16h., Venus $4^{\circ}$ S. ; Mars on Dec. 26d. 22h., Mars $4^{\circ}$ N. ; Saturn on Dec. 29d. 11h., Saturn $2^{\circ}$ N. ; Jupiter on Dec. 31d. 7h., Jupiter $4^{\circ} \mathrm{N}$. Jupiter is in opposition to the sun on Dec. 8, and on Dec. 29 Venus attains its greatest brilliancy; the planet is then 38 million miles from the earth. Mercury is a morning star until Dec. 21, then an èvening star. Venus, Mars, Saturn and Uranus are evening stars. Neptune is a morning star and Jupiter is a morning star until Dec. 7, then an evening star. The sun enters the sign Capricornus on Dec. 22, the winter solstice. About this time of the year we have the interesting phenomenon of the mornings decreasing in length while the afternoons and the whole periods from sunrise to sunset are increasing; this, as is well known, is due to the equation of time. The first magnitude star $\alpha$ Tauri (Aldebaran) is occulted on Dec. 30d. 22h. $23.4 \mathrm{~m}$., reappearance occurring at 23h. $46 \cdot 6 \mathrm{~m}$. The Geminid meteor shower is active during Dec. 7-15, the radiant being close to $\alpha$ Geminorum. Many interesting objects can be seen during the month, such as the great nebulæ of Orion and Andromeda, the open star clusters of Perseus, the Pleiades and the Hyades, and many well-known double stars and variable stars.

\section{Announcements}

Prof. Bjorn Helland-Hansen, the well-known hydrographer and head of the Meteorological Institute of Bergen, was arrested some six months ago and is still in prison.

THe title of professor of mining geology in the University of London has been conferred on Dr. W. R. Jones, in respect of the post held by him at the Imperial College of Science and Technology.

Prof. F. C. Bartiett, professor of experimental psychology in the University of Cambridge, has been appointed a member of the Medical Research Council in the vacancy caused by the death of Prof. A. J. Clark. 